\title{
EKSPLORASI ETNOMATEMATIKA BATIK TRUSMI CIREBON UNTUK MENGUNGKAP NILAI FILOSOFI DAN KONSEP MATEMATIS
}

\author{
Arwanto, M.Pd \\ Universitas Muhammadiyah Cirebon \\ Email : adearwan49@gmail.com
}

\begin{abstract}
Abstrak
Etnomatematika merupakan studi tentang ide-ide matematika dari masyarakat tradisional yang diterapkan dalam masyarakat tertentu, etnomatematika merupakan matematika yang dipraktikkan oleh kelompok budaya seperti masyarakat perkotaan dan pedesaan, kelompok buruh, anak-anak dari kelompok usia tertentu, masyarakat adat, dan lainnya. Batik Trusmi berhasil menjadi ikon batik dalam koleksi kain nasional. Batik Cirebon sendiri termasuk golongan Batik Pesisir, namun juga sebagian batik Cirebon termasuk dalam kelompok batik keraton. Hal ini dikarenakan Cirebon memiliki dua buah keraton yaitu Keratonan Kasepuhan dan Keraton Kanoman, yang konon berdasarkan sejarah dari dua keraton ini muncul beberapa desain batik Cirebonan Klasik yang hingga sekarang masih dikerjakan oleh sebagian masyarakat desa Trusmi di antaranya seperti motif Mega Mendung, Paksinaga Liman, Patran Keris, Patran Kangkung, Singa Payung, Singa Barong, Banjar Balong, Ayam Alas, Sawat Penganten, Katewono, Gunung Giwur, Simbar Menjangan, Simbar Kendo, yang dapat di explorasi etnomatematikanya untuk mengungkap nilai filosofi yang luhur dan konsep matematis.Penelitian ini adalah penelitian kualitatif dengan menggunakan metode etnografi. Tujuan penelitian ini untuk mengunkap filosofi dan konsep matematika.
\end{abstract}

Kata Kunci : Batik Trusmi, Etnomatematika

\section{PENDAHULUAN}

Budaya merupakan suatu kebiasaan yang mengandung unsru-unsur nilai penting dan fundamental yang diwariskan dari generasi-kegenasi. Kebiasaan-kebiasaan yang dilakukan tidak lepas dari penerapan konsep matematika, sehingga memberikan hasil unik dan beragam. Hal ini terlihat dari bentuk hasil budaya yang ada khususnya di Indonesia seperti kesenian, bentuk bangunan, ukiran, perhiasan. " Sehingga matematika merupakan bagian dari budaya dan sejarah”. (Fathani, 2009:87)

Batik Trusmi adalah istilah yang merujuk pada batik khas Cirebon yang berpusat di daerah Trusmi, Kabupaten Cirebon. Batik Cirebon memiliki ciri khas batik pesisiran dengan keunikannya berupa motif dan warna yang tentunya berbeda dengan batik lain di Indonesia. Keindahan Batik Trusmi telah dikenal luas hingga ke mancanegara sehingga menjadi satu kebanggaan bagi masyarakat Cirebon. Mengenal dan memperkenalkan Batik Trusmi bisa dimulai dari sejarah Batik Trusmi itu sendiri. 
Batik Cirebon sebagai sebuah industri telah tertelusuri oleh beberapa sejarawan dan seniman hingga ke akhir abad 19 atau awal abad 20. Meningkatnya ekonomi Cirebon kala itu menjadi salah satu penyebab lahirnya Batik Cirebon sebagai sebuah industri. Pun demikian, sejarah Batik Cirebon telah tercatat hingga di masa Kerajaan Cirebon di abad 14. Berbagai cerita dan legenda yang lahir dan beredar mengenainya cukup menarik untuk disimak.

Sebagaimana asal muasal kata Cirebon dan Grage, ada berbagai versi mengenai kata Trusmi yang tercatat dalam tulisan-tulisan maupun tutur kata masyarakat Cirebon. Satu hal yang pasti, masyarakat Trusmi mempercayai dengan keyakinannya bahwa mereka merupakan keturunan dari Mbah Buyut Trusmi, Ki Buyut Trusmi, atau Pangeran Walangsungsang Cakrabuana atau lebih dikenal sebagai Mbah Kuwu Cerbon. Saat ini, Trusmi adalah sebuah nama desa di wilayah kecamatan Plered, Kabupaten Cirebon yang mana terdapat komplek situs pemakaman Ki Buyut Trusmi. Untuk mengenang dan menghormatinya, setiap tahun terdapat ajang yang dikenal dengan sebutan Trusmian, merupakan upacara khidmat di situs pemakaman Ki Buyut Trusmi yang kemudian diramaikan oleh ajang budaya festival arak-arakan dan pacuan kuda. Ada juga upacara Ganti Welid (ganti rumput) dan Ganti Sirap (ganti atap) setiap empat tahun.

Bangsa Indonesia merupakan bangsa yang memiliki berbagai macam budaya, salah satu budaya yang berkembang dan menjadi sorotan dunia adalah batik yang telah di tetapkan oleh UNESCO sebagai Masterpieces of the Oral and Intangibel Heritage of Humanity pada tanggal 2 Oktober 2009. Indonesia Menetapkan bahwa pada tanggal 2 Oktober adalah hari Batik Nasional sebagai wujud kebanggaan bangsa Indonesia terhadap batik yang telah mendapatkan pengakuan dunia dan menjadi warisan budaya yang patut dikembangkan.

Matematika telah memegang peranan dalam kehidupan dan telah manjadi aktivitas manusia dalam kehidupan sehari-hari. "Mathematics as human activites" (Soedjadi, 2007:6). Begitu juga didalam matematika telah menjadi subjek atau bahan ajar yang penting yang harus didapatkan oleh peserta didik, maka akan melahirkan ethomathematics (Sabilirosyad, 2013).

Etnomathematics dalam bahasa Indonesia dikenal dengan istilah etnomatematika. Etnomatematika merupakan studi tentnag ide-ide matematika dari masyarakat tradisional (Ascher, 1991). Sedangkan D’Ambrosio (dalam Chahine dan Kinuthia, 2013) mengungkapkan etnomatematika merupakan matematika yang dipraktikkan oleh 
kelompok budya seperti masyarakat perkotaan dan pedesaan, kelompok buruh, anak-anak dari kelompok usia tertentu, masyarakat adat, dan lainnya.Menurut Suwarsono (2015:2) : Etnomatematika (Ethnomthematics) adalah Studi tentang matematika yang muncul atau digunakan dalam kelompok-kelompok etnis masyarakat tertentu.Etnomatematika diperkenalkan oleh D'Ambrosio, seorang matematikawan Brasil pada tahun 1977. Definisi etnomatematika menurut D'Ambrosio adalah: Secara bahasa, awalan "ethno" diartikan sebagai sesuatu yang sangat luas yang mengacu pada konteks sosial budaya, termasuk bahasa, jargon, kode perilaku, mitos, dan symbol. Kata dasar "mathema" cenderung berarti menjelaskan, mengetahui, memahami, dan melakukan kegiatan seperti pengkodean, mengukur, mengklasifikasi, menyimpulkan, dan pemodelan. Akhiran "tics “ berasal dari techne, dan bermakna sama seperti teknik. Sedangkan secara istilah etnomatematika diartikan sebagai: matematika yang dipraktekkan diantara kelompok budaya diidentifikasi seperti masyarakat nasional suku, kelompok buruh, anak-anak dari kelompok usia tertentu dan kelas profesional" (D'Ambrosio, 1985). Dari definisi tersebut maka ethnomatematika memiliki pengertian yang lebih luas dari hanya sekedar ethno (etnik) maka etnomatematika didefinisikan sebagai antropology budaya (culture antropology of mathematics) dari matematika dan pendidikan matematika.

Oleh karena tumbuh dan berkembang dari budaya, keberadaan etnomatematika seringkali tidak disadari oleh masyarakat penggunanya. Hal ini disebabkan, etnomatematika seringkali terlihat lebih "sederhana" dari bentuk formal matematika yang dijumpai di sekolah. Masyarakat daerah yang biasa menggunakan etnomatematika mungkin merasa tidak percaya diri dengan warisan nenek moyangnya, karena matematika dalam budaya ini, tidak dilengkapi definisi, teorema, dan rumus-rumus seperti yang biasa ditemui di matematika akademik.

D'Ambrosio (1985) menyatakan bahwa tujuan dari adanya etnomatematika adalah untuk mengakui bahwa ada cara-cara berbeda dalam melakukan matematika dengan mempertimbangkan pengetahuan matematika akademik yang dikembangkan oleh berbagai sektor masyarakat serta dengan mempertimbangkan modus yang berbeda dimana budaya yang berbeda merundingkan praktek matematika mereka (cara mengelompokkan, berhitung, mengukur, merancang bangunan atau alat, bermain danlainnya).

\section{METODE PENELITIAN}


Jenis Penelitian ini adalah penelitian kualitatif dengan pendekatan etnografi. Penelitian kualitatif (Suwarsono, 2015: 2) adalah penelitian yang menggunakan paradigma nauralistik, dapat digunakan karena peneliti ingin secara intensif ikut serta partisipasi dilapangan, mencatat secara hati-hati apa yang terjadi, melakukan analisis reflektif terhadap berbagai dokumen yang ditemukan dilapangan, dan membuat penelitian secara mendetail. Sedangkan pendekatan etnografi merupakan pendekatan empiris dan teoritis yang bertujuan mendapatkan deskripsi dan analisis mendalam tentang Batik Trusmi Cirebon serta nilai-nilai filosofis dan konsep matematisnya berdasarkan penelitian lapangan (fieldwork) yang intensif. Dalam penelitian ini, pendekatan etnografi digunakan untuk menggambarkan, menjelaskan dan menganalisis konsep-konsep matematika yang terdapat pada Batik Trusmi Cirebon.

\section{HASIL DAN PEMBAHASAN}

Hasil dari Penelitian ini berupa gambaran tentang nama dan jenis batik Trusmi Cirebon berupa berbagai jenis motif yang mengandung nila-nilai Matematis.

Apabila motif batik trusmi Cirebon ini dicermati dengan baik, maka dapat ditemukan adanya beberapa konsep matematika yang terkandung di dalamnya. Konsepkonsep Matematika tersebut antara lain konsep simetri, transformasi (refleksi, translasi, dan rotasi), kekongruenan, dan kesebangunan. Tidak hanya dapat diperhatikan dari motifnya, namun konsep matematika ini secara tidak langsung dapat diperhatikan pada cara pembuatan motif ini, tanpa disadari bahwa budaya masyarakat pengrajin batik telah menanamkan nilai-nilai matematis di dalamnya. Adapun kajian mengenai konsep-konsep matematika pada motif batik diuraikan sebagai berikut.

\section{Konsep Simetri pada Motif Batik Tusmi Cirebon}

Konsep simetri yang dimaksudkan di sini adalah simetri lipat. Salah satu cara pembuatan motif batik yaitu dengan membuat sketsanya dengan terlebih dahulu membuat motif-motif tertentu. Sketsa ini biasanya dibuat dengan kertas. Sebagai contoh pada pembuatan motif batik seperti Gambar C.1. Masih banyak jenis motif batik yang dikembangkan dengan metode ini. 


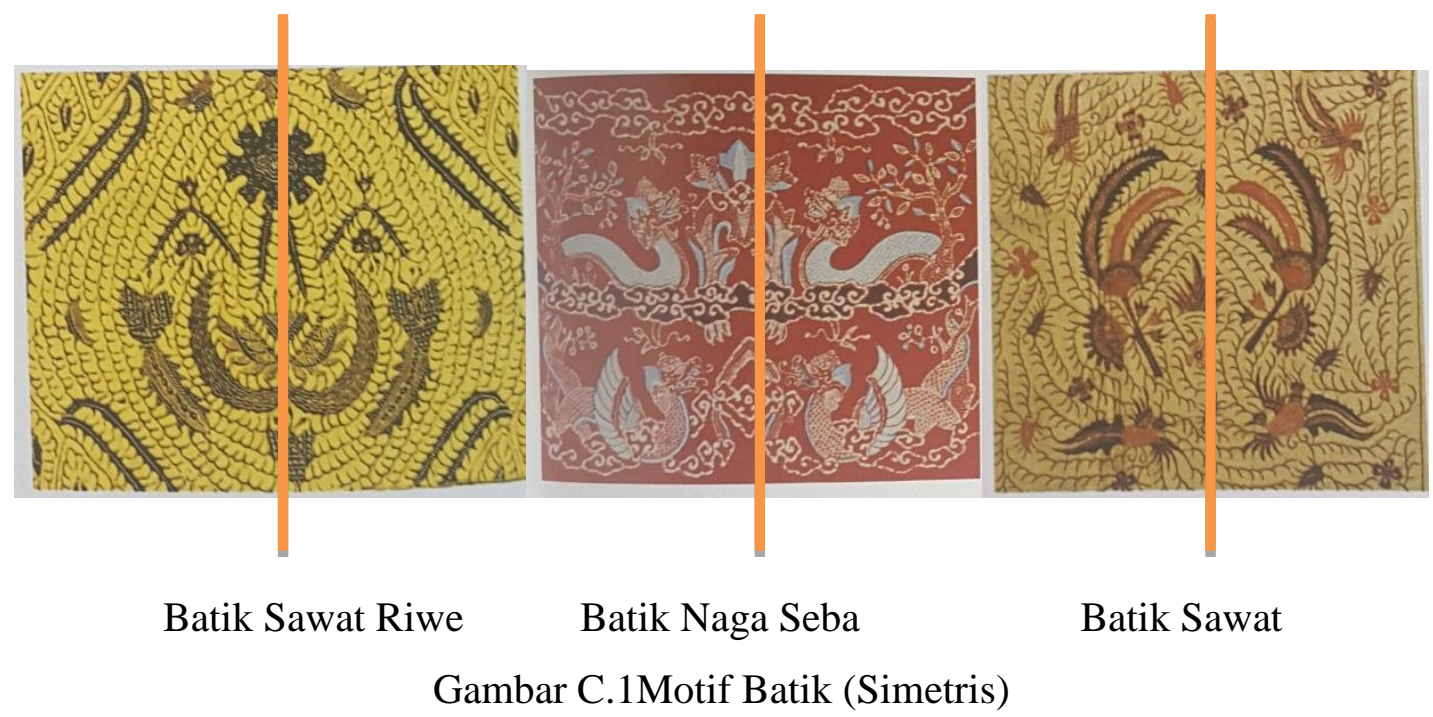

Gambar C.1 merupakan motif batik yang simetris, garis tebal di atas menunjukkan sumbu simetri dari motif batiktrusmi tersebut. Filosofis Batik ini adalah mengambarkan kekuatan besar dari tiga negara yang bersinergi di Cirebon yakni kebudayaan Cina, Arab dan eropa.

\section{Konsep Transformasi pada Motif BatikTusmi Cirebon}

Pada motif batik Trusmi Cirebon terkandung pula konsep transformasi, seperti refleksi, translasi, dan rotasi. Kajian mengenai konsep-konsep ini pada motif batik diuraikan sebagai berikut.

\section{a) Konsep Refleksi pada Motif Batik}

Selain dengan metode seperti di atas dalam membuat motif batik, dapat juga digunakan metode sederhana lainnya yaitu dengan menerapkan konsep refleksi.. Misalnya seperti pembuatan motif pada Gambar C.2. Pada Gambar ini cukup dibuat sketsa motif a, yang selanjutnya sketsa ini ditaruh disebelah kanan, bawah atau posisi tertentu lainnya yang akhirnya akan memperoleh motif batik yang utuh seperti Gambar C.2. 


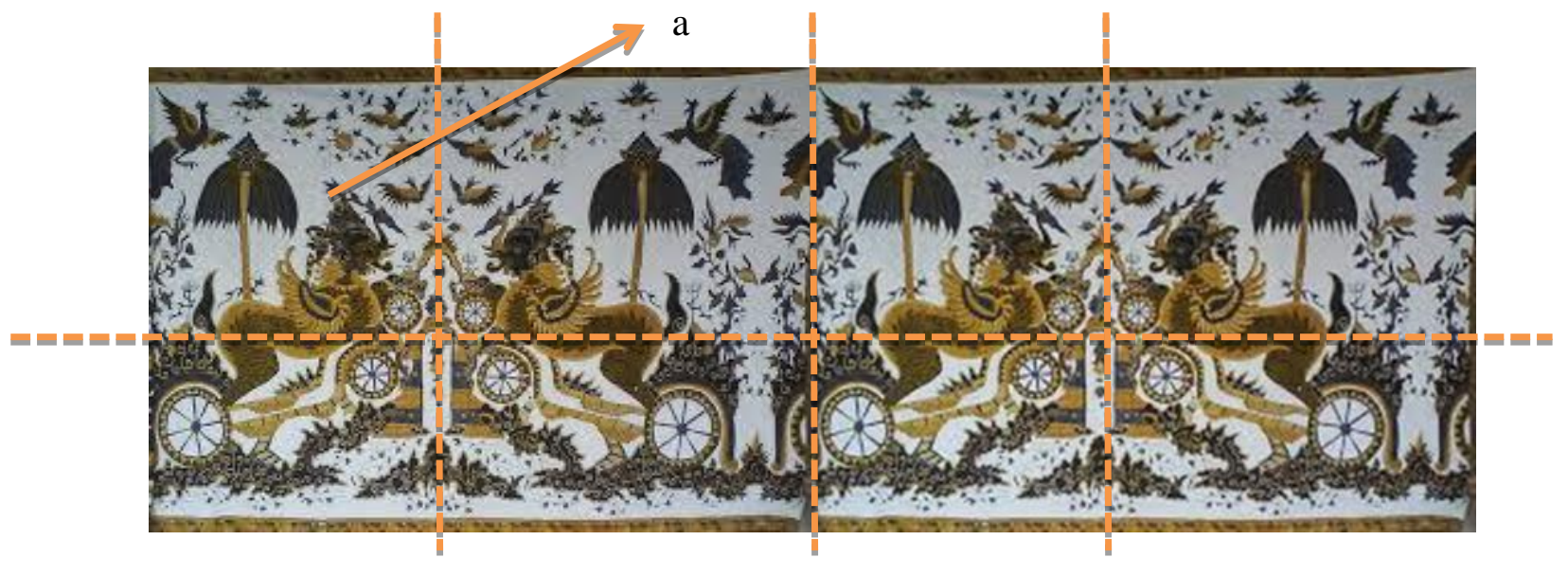

Batik Paksi Naga Liman Cirebon

Gambar C. 2 Motif Batik (Refleksi)

\section{b) Konsep Translasi pada Motif BatikTrusmi}

Dalam konsep lain yang digunakan dalam pembuatan motif batik Trusmi cirebon adalah konsep translasi. Dengan memindahkan atau menggeser sketsa motif batik ke posisi tertentu, tentunya cukup jelas menggambarkan bahwa konsep translasi telah diterapkan dalam pembuatan motif batik. Sebagai contoh motif batik pada Gambar C.3. Pada Gambar C.3, motif a digeser sekian satuan ke kanan sehingga diperoleh motif a', selanjutnya a' digeser ke kanan sekian satuan lagi sehingga diperoleh a', demikian seterusnya. Pada akhirnya diperoleh motif batik Liris, seperti Gambar C.3.

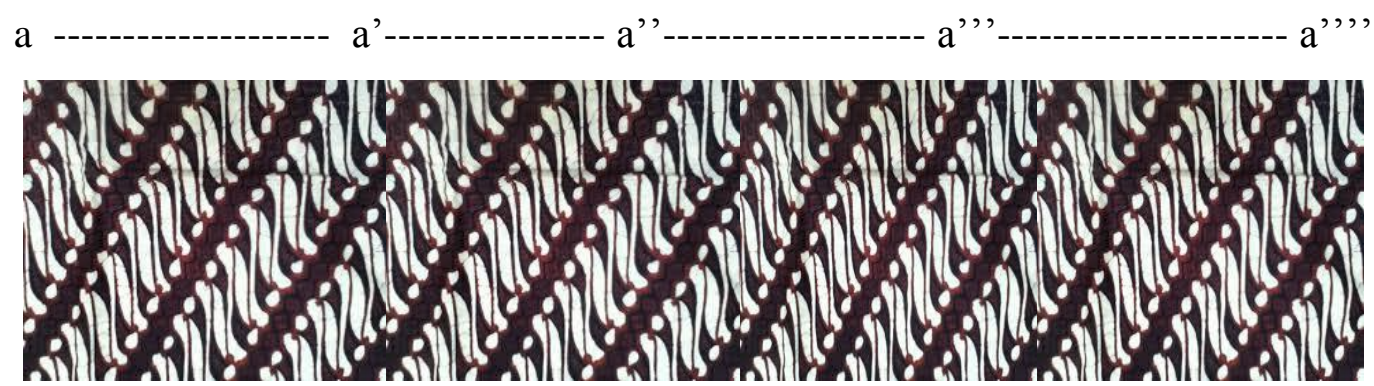

Batik Liris Trusmi Cirebon 


\section{c) Konsep Rotasi pada Batik Trusmi Cirebon}

Pembuatan motif batik juga dapat dikaitkan dengan konsep rotasi pada bangun datar. Dimana konsep rotasi yang dimaksud didapat dengan cara memutar motif yang dibuat sesuai dengan sumbunya. Sebagai contoh, perhatikan motif batik pada Gambar C.4. Pada Gambar ini, motif a terlebih dahulu dicerminkan terhadap sumbu cermin vertikal yaitu $l$, sehingga diperoleh a', a' ini selanjutnya diputar 180 derajat sehingga diperoleh a', Dari proses ini, diperoleh motif batik pada Gambar C.4.

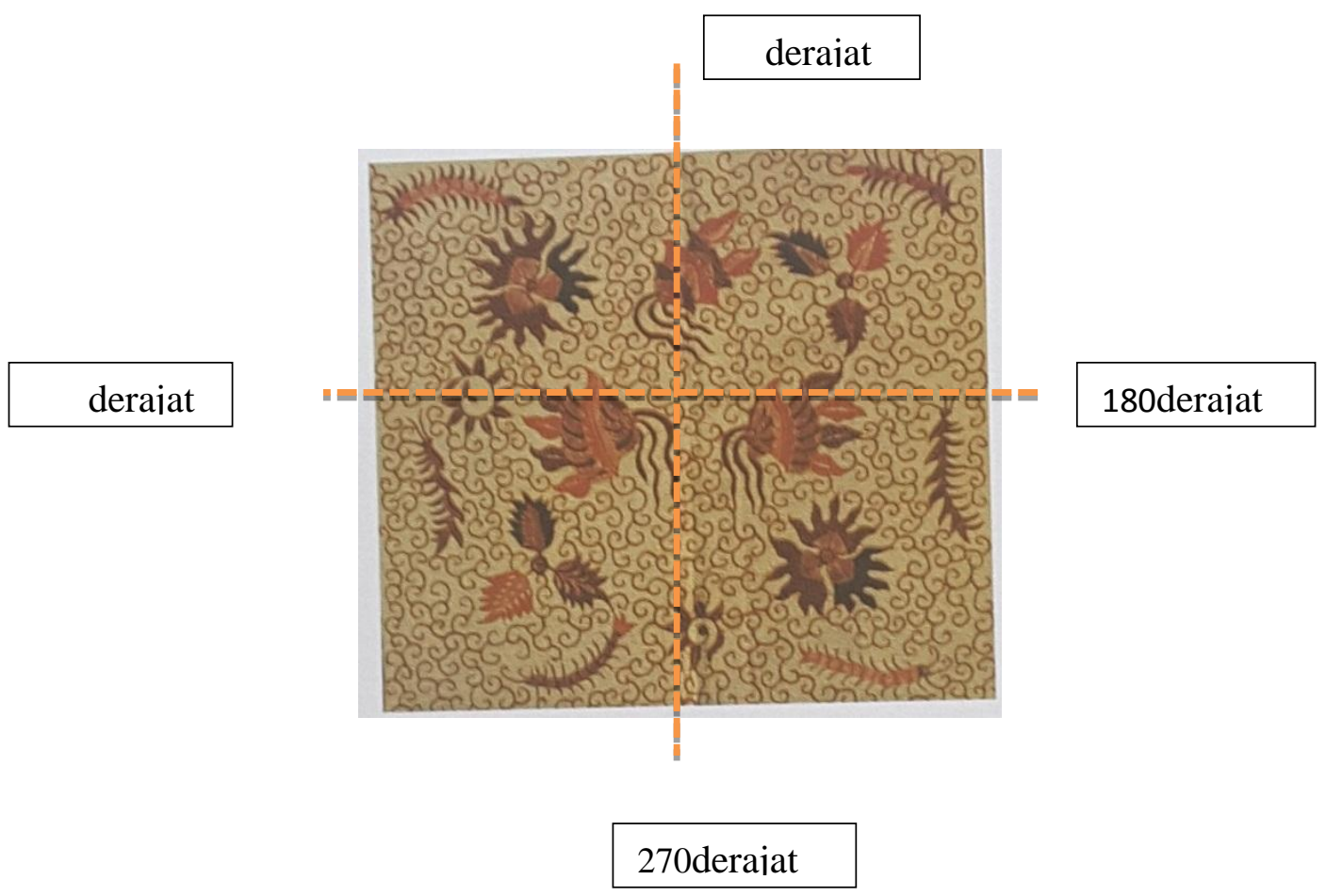

Batik Ukel Romo Trusmi Cirebon

Gambar C.4 Motif batik (Rotasi)

\section{d) Konsep Dilatasi pada Motif Batik}

Dengan membuat sketsa motif batik trusmi cirebon yang kemudian dilakukan tindakantindakan tertentu, seperti dicerminkan, digeser, diputar untuk mebuat batik tentu 
telah menggambarkan dengan jelas bahwa konsep-konsep transformasi telah diterapkan. Selain tindakan-tindakan ini, juga dapat dilakukan tindakan-tindakan lainnya seperti menyalin sketsa kedalam ukuran yang lebih kecil atau lebih besar, yang selanjutnya digunakan untuk membuat motif batik yang utuh. Sebagai contoh motif batik pada Gambar C.5. Pada Gambar dibawah ini, motif pada gambar helai bunga digeser kemudian diperbesar, sehingga diperoleh motif batik yang utuh seperti Gambar C.5. 90 derajat, 180,derajat 270 derajat, 360derajat

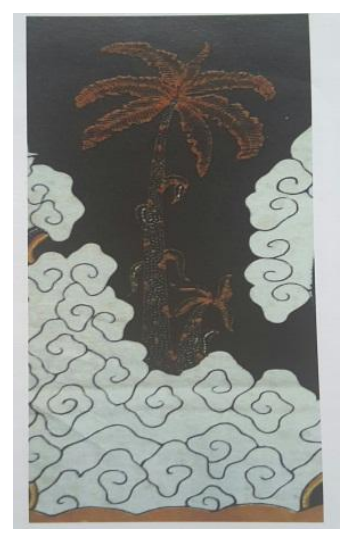

\section{Batik Wadasan Trusmi Cirebon \\ Gambar C.5 Motif Batik (Dilatasi)}

Dari paparan di atas jelas bahwa dalam motif batik juga terkandung konsep dilatasi. Tentu masih banyak motif batik lainnya yang diterapkan dengan menggunakan konsep dilatasi. Jadi, hakikatnya pada pembuatan motif batik tursmi cirebon telah diterapkan konsep transformasi. Bahkan dalam pembuatan motif batik tidak hanya salah satu dari konsep transformasi yang diterapkan, namun beberapa konsep transformasi juga dapat diterapkan sekaligus.

\section{Konsep Kekongruenan pada motif batikTrusmi Cirebon}

Dalam Motif Batik Trusmi Cirebon Selain terdapat konsep simetri dan transformasi, pada motif batik juga terdapat konsep lain yaitu konsep kekongruenan. Salah satu cara untuk menunjukkan bahwa dalam batik tusmi Cirebon terdapat konsep kekongruenan pada motif batik, sketsa yang dibuat kemudian diberikan tindakan, apakah dicerminkan, digeser, atau diputar. Sehingga dengan proses ini, maka diperoleh motif batik lainnya pada posisi lain yang memiliki ukuran dan bentuk yang sama dengan motif batik semula. 
Sebagai contoh yaitu Gambar C.6. Pada Gambar ini, batik tersebut terdiri dari motif batik yang kongruen satu sama lain.

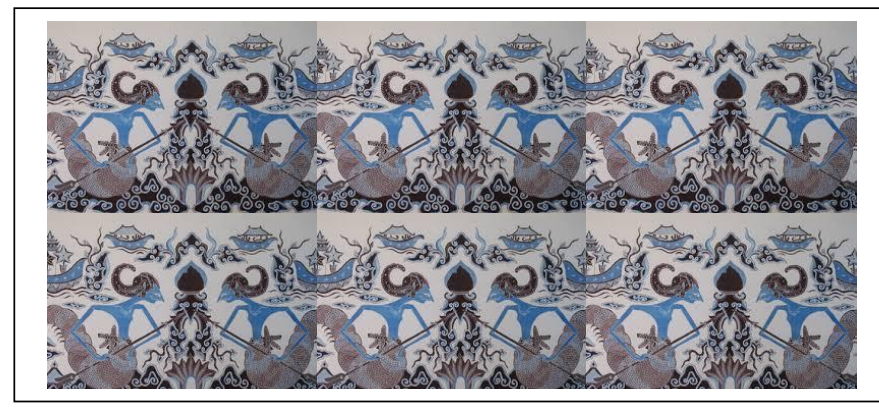

Batik Wayang Cirebon

Gambar C.6 Motif Batik (Kekongruenan)

\section{Konsep Kesebangunan pada Motif BatikTrusmi Cirebon}

Karena pada motif batik terkandung konsep dilatasi, yang merupakan konsep yang sejalan dengan kesebangunan. Maka pada motif batik juga terdapat konsep kesebangunan. Hal ini dapat dicermati pada Gambar diatas, disana terdapat motif batik yang diperbesar ukurannya menjadi sekian kali ukuran semula yang sebanding, ini artinya bahwa bentuk motif batik hasil dilatasi adalah sama dengan bentuk semula namun ukurannya yang sebanding. Hal ini sesuai dengan konsep kesebangunan dari dua buah bangun yaitu bentuk bangun sama namun ukurannya sebanding. Jadi, dari paparan di atas jelas terlihat bahwa pada motif batik terkandung berbagai konsep matematika. Konsep-konsep tersebut antara lain konsep simetri, transformasi (refleksi, translasi, dan rotasi), serta kekongruenan. Dengan memahami etnomatematika motif batik ini tentu dapat memberikan inspirasi kepada pendidik untuk mengembangkan pembelajaran yang menarik dengan menerapkan etnomatematika ini. Beberapa gambaran pembelajaran yang menerapkan etnomatematika ini akan dipaparkan pada bagian berikut.

\section{KESIMPULAN}


Berdasarkan hasil dan pembahasan diatas, dapat disimpulkan bahwa dapat disimpulkan didalam batik trusmi cirebon mengandung unsur-unsur matematis, dianataranya adalah konsep-konsep geometri simetri, transformasi (refleksi, translasi, dan rotasi), serta kekongruenan.

Manfaat dari penelitian ini selain sebagai sumber informasi mengenai tradisi membatik masyarakat budaya trusmi cirebon, juga dapat digunakan sebagai sarana untuk merancang pembelajaran matematika realistik di kampus atau sekolah pada umumnya.

\section{DAFTAR PUSTKA}

Abas, S.J. (2001) Islamic geometrical patterns for the teaching of mathematic of symmetry (Special issue of Syimmetry : Culture and Science). Syimmetry in Ethnomathematics, 12 (1-2), 53-65. Budapest, Hungary: International Symmetry Foundation.

Adam, S. (2002). Ethnomathematics in the Maldivian curriculum. In M. de Monteiro (Ed.), Proceedings of the 2nd International Congress on Ethnomathematics (ICEM2), CD Rom, Ouro Preto, Brazil: Lyrium Comunacacao.

Ascher, M,. (1991). Ethnomathematics: A Multicultural view of mathematical ideas. Pasific Grove. Calivornia.

Astri W, Ayu A.W.T, Budiman.S. (2013) Peran Etnomatematika dalam membangun Karakter Bangsa.Makalah Prosiding Seminar Nasional Matematika dan Pendidikan Matematika. Pendidikan Matematika FMIPA UNY

Andika A, Didi S, Tatang H, Cece R.(2014)Study of Ethnomathematics : A lesson from the Baduy Culture.International Journal of Education and Research Vol. 2 No. 10 October

Bambang, H (2009) Kebudayaan Masyarakat Cirebon dan Religiustas, Prestasi. Jakarta

Barton, B. (1996). Ethnomathematics: Exploring cultural diversity in mathematics. UnpublishedPhD, University of Auckland, Auckland, New Zealand.

Julia Maria \& Jan Van Tiel (2014) The Rainbow of Cirebon, Cultural, Heritage and The History of Cirebon West Java- Indonesia. Yayasan Prima Ardian Tana. Jakarta 